\title{
Recurrent Abdominal Burst after Obstetric Surgical Procedure
}

\author{
Noor A Zulhijayanti ${ }^{1}$, Rozi A Aryananda ${ }^{2}$, Lynda Hariani ${ }^{3}$, Eko B Koendhori ${ }^{4}$, Ernawati Darmawan ${ }^{5}$
}

\begin{abstract}
Introduction: Abdominal burst due to obstetric surgery complications is still a concern because it increases maternal morbidity and mortality. Case description: There are 15 cases with abdominal burst obtained from 3,914 obstetric surgical procedures during 2013 to 2018 in Dr Soetomo General Hospital, with 5 cases (30\%) of recurrent abdominal bursts. Preoperative risk factors are obtained from the host, such as anemia, hypoalbuminemia, and autoimmune diseases. Two recurrent abdominal burst cases occurred after cesarean section, and three cases occurred in hysterectomy after cesarean section, all of which used retention sutures as initial management, and in reality, it did not prevent repeated bursts. The whole case went to emergency surgery, and surgical site infection was obtained as an agent that aggravates the degree of disease. Selection of management and treatment is based on the patient's wound problems. Two cases required intensive and multidisciplinary care and used vacuum-assisted closure (VAC) and modified VAC. There were two patients (6.7\%) who died from sepsis, while three other patients had well-closed wounds, and no complications have been found to date.

Conclusion: One-third of abdominal burst patients in Dr Soetomo General Hospital had recurrence involving long-term multidisciplinary care and required facilities and an optimal environment. The dominant risk factors are obtained from the inferior conditions of the host, such as anemia, hypoalbuminemia, and autoimmune diseases.

Keywords: Obstetric surgical procedure, Recurrent abdominal burst, Vacuum-assisted closure.

Journal of South Asian Federation of Obstetrics and Gynaecology (2019): 10.5005/jp-journals-10006-1715
\end{abstract}

\section{INTRODUCTION}

Abdominal surgery is sometimes done either in an obstetric or gynecology department. Cesarean section is the most common practice in abdominal surgery. In several countries, the number of cesarean section has increased, including that in Indonesia. Although considered safe to avoid maternal-neonatal complications, and despite the improvement in both operation and anesthesia technologies, abdominal burst as one of the cesarean section complications remains a concern, as it increases the number of maternal morbidity and mortality. ${ }^{1}$ Abdominal burst is a postoperative complication that increases morbidity and mortality. ${ }^{2}$ It is defined as an open postoperative wound in the abdomen, that in $20 \%$ to $45 \%$ of cases leads to internal organ release, which relates to the mortality rate in the perioperative period. ${ }^{3}$ Mortality rate in abdominal burst ranges from $15 \%$ to $45 \%$, while the incidence rate ranges from $0.4 \%$ to $3.5 \%$ of all laparotomy surgeries. ${ }^{4}$ Most cases happen in the second week and the peak in the 10th-day postoperation. ${ }^{5}$ The separated sutures wound in the abdomen both partial, and complete must be treated immediately.

\section{Materials and Methods}

This case report is a descriptive retrospective study. Fifteen cases of abdominal burst were found between January 2013 and June 2018 among 3914 per abdominal surgeries in obstetric department, we explained the risk factors (preoperative, operative, and postoperative), and the management of the cases, then we found five recurrent abdominal burst cases that happened after obstetric per abdominal surgery in Dr Soetomo General Hospital, either post-cesarean section or hysterectomy. The data was obtained through register data, serial morning case reports, operation reports, and medical records. The ethical clearance certificate was obtained from the ethical committee in Dr Soetomo General Hospital.
1,2,5 Department of Obstetrics and Gynecology, Dr Soetomo General Hospital, Faculty of Medicine, Airlangga University, Surabaya, Indonesia ${ }^{3}$ Plastic and Esthetic Reconstruction Surgery Department, Dr Soetomo General Hospital, Faculty of Medicine, Airlangga University, Surabaya, Indonesia

${ }^{4}$ Clinical Microbiology Department, Dr Soetomo General Hospital, Faculty of Medicine, Airlangga University, Surabaya, Indonesia

Corresponding Author: Noor A Zulhijayanti, Department of Obstetrics and Gynecology, Dr Soetomo General Hospital, Faculty of Medicine, Airlangga University, Surabaya, Indonesia, Phone: +62 82156777333, e-mail: syifa.zulhijayanti@gmail.com

How to cite this article: Zulhijayanti NA, Aryananda RA, Hariani L, et al. Recurrent Abdominal Burst after Obstetric Surgical Procedure. J South Asian Feder Obst Gynae 2019;11(5):321-328.

Source of support: Nil

Conflict of interest: None

\section{Case Description}

From 15 cases of abdominal bursts happening after obstetric surgeries in Dr Soetomo General Hospital from January 2013 until June 2018, most of the patients aged 20 to 35 years (60\%), with multiparity (87\%). The characteristics of post-obstetric-operation abdominal burst in Dr Soetomo General Hospital, based on preoperative predisposition factors, dominated mostly by nonobstetric comorbidity, which are anemia and hypoalbuminemia in 12 cases $(80 \%)$ with the mean $\mathrm{Hb}$ of $7.0 \mathrm{~g} / \mathrm{dL}$ and the mean albumin $2.49 \mathrm{~g} / \mathrm{dL}$, followed by thrombocytopenia (33.3\%, mean thrombocyte $42.340 / \mu \mathrm{L})$, hypertension $(26.7 \%)$, obesity $(26.7 \%)$, autoimmune disease with steroid use (20\%), and diabetes mellitus (13.3\%). While the preoperative obstetric complication was mostly of puerperal sepsis $(40 \%)$ followed by postpartum hemorrhage (33.3\%). From 15 cases, 7 patients were found with Pfannenstiel 
incision (46.7\%), and the meantime of operation before abdominal burst happen was 129 minutes, mean of bleeding was $893 \mathrm{~mL}$, and two-third of the cases (66.7\%) were done by the resident/ trainee. The thread used to close the fascia in two-third of cases is a polyglactin 910 (Safil $^{\oplus}$ ) multifilament thread, using the basting technique. Abdominal burst is found mainly in patients underwent hysterectomy post caesarian section (73\%), or directly after caesarian section (20\%) with surgery area infection in most cases (93.3\%) and increased intra-abdominal pressure due to ileus (40\%) and cough (26.7\%) while in postoperative care. Five patients (33.3\%) with abdominal burst were readmitted to the hospital with an infection in the surgery area (Table 1).

In all abdominal burst cases reported, intravenous prophylaxis antibiotic cefazolin was injected before incision (dose $2 \mathrm{~g}$ in 30 minutes). While the antibiotic injection postoperatively before abdominal burst was done in 11 patients, 2 patients were not given the postoperative antibiotic injection, and the postoperative antibiotic injection data for the other 2 was not found. The initial antibiotic administration was given empirically, before culture (Table 2).

In five cases (30\%), recurrent abdominal burst happened after repairing. In all recurrent abdominal burst cases, postoperative infection predisposition factors were found. Two deaths (13.3\%) were found on day 23 and 39 due to sepsis.

In five recurrent abdominal bursts, culture of tissue and pus was done serially, with gram-negative bacteria as the main pathogen (Table 3).

Proteus mirabilis is a pathogen in the urinary tract, can also cause wound infection, sepsis, and pneumonia in hospital care patients. Another pathogen that slows down the healing process in the abdominal burst is ESBL (+) bacteria, e.g., Escherichia coli and Klebsiella pneumoniae (Table 4).

\section{Discussion}

In this case report, we examine wound complication incidence after 3,914 per abdominal surgeries in obstetric department done in Dr Soetomo General Hospital from January 2013 until June 2018 , shows the abdominal burst rate is $0.4 \%$, and the mortality rate of all abdominal burst cases is $6.7 \%$, which increased the maternal death rate in RSUD Dr Soetomo by $0.02 \%$. This confirms the international data showing that abdominal burst incidence ranges from $0.4 \%$ to $3.5 \%$ and is related to the high mortality rate, reaching $45 \%{ }^{6}$ This case shows one-third (30\%) of abdominal burst patients experienced recurrency that prolonged the hospital care and affected the physical, mental, and social conditions either in patients or their families.

Postoperative abdominal burst, in Dr Soetomo General Hospital mostly occurs during 8 to 14 days post-operation with a mean onset of 10 days, this is consistent with the literature showing that the peak of abdominal burst is at day 10 post-operation. ${ }^{5}$ Abdominal burst is related to preoperative, operative, and postoperative predisposition factors, e.g., nutrition, comorbidity, labor process, infection, operation technique, and postoperative care, stated in this study. The majority of preoperative predisposition factors are usually hosted factors, e.g., anemia (80\%), and hypoalbuminemia (80\%). This corresponds with previous studies, stating that major preoperative predisposition factors, e.g., anemia, hypoproteinemia, hypoalbuminemia is related to increment in abdominal burst incidence rate. Anemia ( $\mathrm{Hb}$ below $10 \mathrm{~g} / \mathrm{dL}$ ) affects the healing process as hemoglobin plays a role in distributing oxygen to the
Table 1: Characteristics of abdominal burst patients in Dr Soetomo General Hospital

\begin{tabular}{|c|c|c|}
\hline Variable & $\begin{array}{l}\text { Abdominal burst } \\
(n=15)(\%)\end{array}$ & $\begin{array}{l}\text { Recurrent abdominal } \\
\text { burst }(n=5)(\%)\end{array}$ \\
\hline$<20$ years & $1(7)$ & $1(20)$ \\
\hline 20-35 years & $9(60)$ & $3(60)$ \\
\hline$>35$ years & $5(33)$ & $1(20)$ \\
\hline \multicolumn{3}{|l|}{ Parity status } \\
\hline Primipara & $2(13)$ & $0(0)$ \\
\hline Multipara & $13(87)$ & $5(100)$ \\
\hline \multicolumn{3}{|c|}{ Location of initial obstetric care } \\
\hline $\begin{array}{l}\text { Dr Soetomo General } \\
\text { Hospital }\end{array}$ & $7(47)$ & $3(60)$ \\
\hline Other hospital & $8(53)$ & $2(40)$ \\
\hline \multicolumn{3}{|l|}{$\begin{array}{l}\text { Preoperative risk factors } \\
\text { (Non-obstetric) }\end{array}$} \\
\hline Anemia & $12(80)$ & $3(60)$ \\
\hline Thrombocytopenia & $5(33.3)$ & $3(60)$ \\
\hline Hypoalbuminemia & $12(80)$ & $3(60)$ \\
\hline Diabetes mellitus & $2(13.3)$ & $1(20)$ \\
\hline Hypertension & $4(26.7)$ & $1(20)$ \\
\hline Obesity & $4(26.7)$ & $1(20)$ \\
\hline $\begin{array}{l}\text { Autoimmune disease } \\
\text { and steroid use }\end{array}$ & $3(20)$ & $3(60)$ \\
\hline Malignancy & $0(0)$ & $0(0)$ \\
\hline $\begin{array}{l}\text { Lung disease } \\
\text { (Obstetric) }\end{array}$ & $0(0)$ & $0(0)$ \\
\hline Puerperal sepsis & $6(40)$ & $1(20)$ \\
\hline $\begin{array}{l}\text { Postpartum } \\
\text { hemorrhage }\end{array}$ & $2(13.3)$ & $2(40)$ \\
\hline \multicolumn{3}{|l|}{ Postoperative risk factors } \\
\hline Hospital readmission & $5(33.3)$ & $1(20)$ \\
\hline Cough & $4(26.7)$ & $3(60)$ \\
\hline $\begin{array}{l}\text { Operation area infec- } \\
\text { tion }\end{array}$ & $14(93.3)$ & $5(100)$ \\
\hline Ileus & $6(40)$ & $3(60)$ \\
\hline Organ rupture & $2(13.3)$ & $0(0)$ \\
\hline \multicolumn{3}{|l|}{ Abdominal burst onset } \\
\hline$<7$ days & $5(33.3)$ & $2(40)$ \\
\hline 8-14 days & $6(40)$ & $2(40)$ \\
\hline$>14$ days & $4(26.7)$ & $1(20)$ \\
\hline Mean & 10 days & 11 days \\
\hline \multicolumn{3}{|l|}{ Operative risk factors } \\
\hline \multicolumn{3}{|l|}{ Incision type } \\
\hline Midline & $5(33.3)$ & $2(40)$ \\
\hline Pfannenstiel & $7(46.7)$ & $2(40)$ \\
\hline T-inverse & $3(20)$ & $1(20)$ \\
\hline \multicolumn{3}{|l|}{ Operation duration } \\
\hline$<60$ minutes & $4(26.7)$ & $2(40)$ \\
\hline $60-180$ minutes & $5(33.3)$ & $2(40)$ \\
\hline$>180$ minutes & $6(40)$ & $1(20)$ \\
\hline Mean & $129 \mathrm{~min}$ & $98 \mathrm{~min}$ \\
\hline
\end{tabular}


Contd...

\begin{tabular}{|c|c|c|}
\hline Variable & $\begin{array}{l}\text { Abdominal burst } \\
(n=15)(\%)\end{array}$ & $\begin{array}{l}\text { Recurrent abdomina } \\
\text { burst }(n=5)(\%)\end{array}$ \\
\hline \multicolumn{3}{|l|}{ Hemorrhage } \\
\hline$<1000 \mathrm{~mL}$ & $9(60)$ & $3(60)$ \\
\hline $1000-3000 \mathrm{~mL}$ & $6(40)$ & $2(40)$ \\
\hline$>3000 \mathrm{~mL}$ & $0(0)$ & $0(0)$ \\
\hline Mean & $893 \mathrm{~mL}$ & $1240 \mathrm{~mL}$ \\
\hline \multicolumn{3}{|l|}{ Operator } \\
\hline Resident/trainee & $10(66.7)$ & $3(60)$ \\
\hline Specialist/supervisor & $5(33.3)$ & $2(40)$ \\
\hline \multicolumn{3}{|l|}{ Thread to close fascia } \\
\hline Monofilament & $1(8.3)$ & $1(20)$ \\
\hline Multifilament & $11(91.7)$ & $4(80)$ \\
\hline \multicolumn{3}{|l|}{ Technique used } \\
\hline Basting & $12(100)$ & $5(100)$ \\
\hline Interrupted & $0(0)$ & $0(0)$ \\
\hline \multicolumn{3}{|l|}{ Operation type } \\
\hline Hysterectomy & $11(73)$ & $4(80)$ \\
\hline Cesarean section & $3(20)$ & $1(20)$ \\
\hline Colostomy post-CS & $1(7)$ & $0(0)$ \\
\hline \multicolumn{3}{|l|}{ Operation condition } \\
\hline Elective & $0(0)$ & $0(0)$ \\
\hline Emergency & $15(100)$ & $5(100)$ \\
\hline
\end{tabular}

Table 2: Characteristics of postoperative antibiotic administration before abdominal burst onset

\begin{tabular}{ll}
\hline Antibiotics & Case \\
\hline Triple drugs combination (ceftriaxone, metronidazole, & 5 \\
gentamicin) & \\
Cefoperazone-sulbactam & 3 \\
Levofloxacin & 1 \\
Meropenem & 2 \\
\hline
\end{tabular}

Table 3: Characteristics of bacteria based on tissue and pus culture in recurrent abdominal burst cases

\begin{tabular}{lll}
\hline & Tissue culture & Pus culture \\
\hline Proteus mirabilis & 3 & 3 \\
Escherichia coli ESBL (+) & 2 & 2 \\
Pseudomonas aeruginosa & 1 & 0 \\
Enterobacter cloacae & 1 & 1 \\
Acinetobacter baumannii & 1 & 2 \\
Klebsiella pneumoniae ESBL (+) & 0 & 1 \\
Enterococcus faecalis & 0 & 1 \\
Burkholderia gladioli & 0 & 1 \\
\hline
\end{tabular}

regenerating tissue. The same goes with hypoproteinemia and hypoalbuminemia, where amino acid in large number is needed in the tissue healing process. ${ }^{2}$

Of 15 cases, 7 patients were operated using Pfannenstiel incision (46.7\%). This is different from the previous study done by Burger and Spiliotis, where midline incision has a bigger incidence rate than the transversal incision for abdominal burst. Midline incision cut the aponeurotic fiber, while transversal incision cut between the fibers. In midline incision, contraction on the abdominal wall will give pressure and can induce a new wound on the lateral of the suture, while with the transversal incision, the sutures will be joined. ${ }^{7,8}$ Two-thirds of abdominal burst cases $(66.7 \%)$ were done by the residents/trainees. Not to be forgotten that the skill of the operator and the technique used can also affect the outcome. Most of the obstetric abdominal burst cases happen after the hysterectomy post-cesarean section (73\%). This condition is found in patients with post-cesarean section surgery, causing puerperal sepsis and making hysterectomy the only method to control infection.

One study by Amini et al., in 2013, in Pakistan, saying that abdominal burst prevalence is lower in emergency surgeries (14.89\%) compared to elective surgeries $(2.7 \%) .{ }^{9}$ The same condition was found in this case report, where the cases are all complications of obstetric elective surgeries with the meantime of operation is 129 minutes. Not to be forgotten that patients condition needing emergency surgery are mainly not optimal and at a higher risk of contamination compared to elective surgery. In addition, the concert of the surgery may be affected that can lead to suboptimal closure of the abdomen at the ending of the procedure. ${ }^{6}$ In this study, majority of bleeding was $<1000 \mathrm{~mL}$, and the mean was $893 \mathrm{~mL}$. Great number of bleeding in surgery and history of abdominal tampon usage is known to increase the risk of postoperative infection and sepsis.

Another important thing is that the strength of the wound stretch will increase to approximately $50 \%$ in week 4 post-operation. After 6 to 12 months, wound will achieve $80 \%$ of normal strength. ${ }^{10}$ In five cases of recurrent abdominal burst, only three patients were found with all-layer suture, while in two patients, the fascia was not stitched and was closed only using skin in the later abdominal burst. The outcome is similar to the other patients with layered sutures. The result is the opposite of the previously reported case, series when layered stitches and all-layer technique were compared the result shows the wound dehiscence is lower with the all-layer technique. ${ }^{3}$

All five patients that received hospital care underwent a repair surgery with retention sutures technique. Unfortunately, of five patients, four were reported to have recurrent abdominal burst 6 to 14 days after. Another patient passed away in day one of care after repair with retention suture. This is significant to the study by Gislason and Viste in 1999 that shows retention sutures do not prevent abdominal burst. In $48 \%$ of the cases where retention suture was used, abdominal burst was found, compared to $27 \%$ of patients without retention suture $(p=0.31)$. Retention suture also shows poor outcomes in cosmetics and a higher possibility of pain after surgery. ${ }^{11}$

The suture used needs to have stable power in pulling for at least 6 weeks to allow the wound to have the normal resistance power. ${ }^{11,12}$ Majority of the thread used to close the fascia in patients is polyglactin $910\left(\mathrm{Safil}^{\oplus}\right)$ multifilament thread and mostly done with basting technique. Suture using multifilament thread can increase wound infection and incidence, therefore not recommended.

Besides incision and suture technique, wound infection prevention by using the aseptic technique can also prevent infection, as well as the use of prophylaxis antibiotics. Atraumatic surgery technique, good hemostasis, necrotic tissue debridement can reduce surgery area infection. Among 15 cases, surgery area infection was found in $93.3 \%$ of all cases. Infection in the surgery area causes wet necrotic tissue on the sutures and 


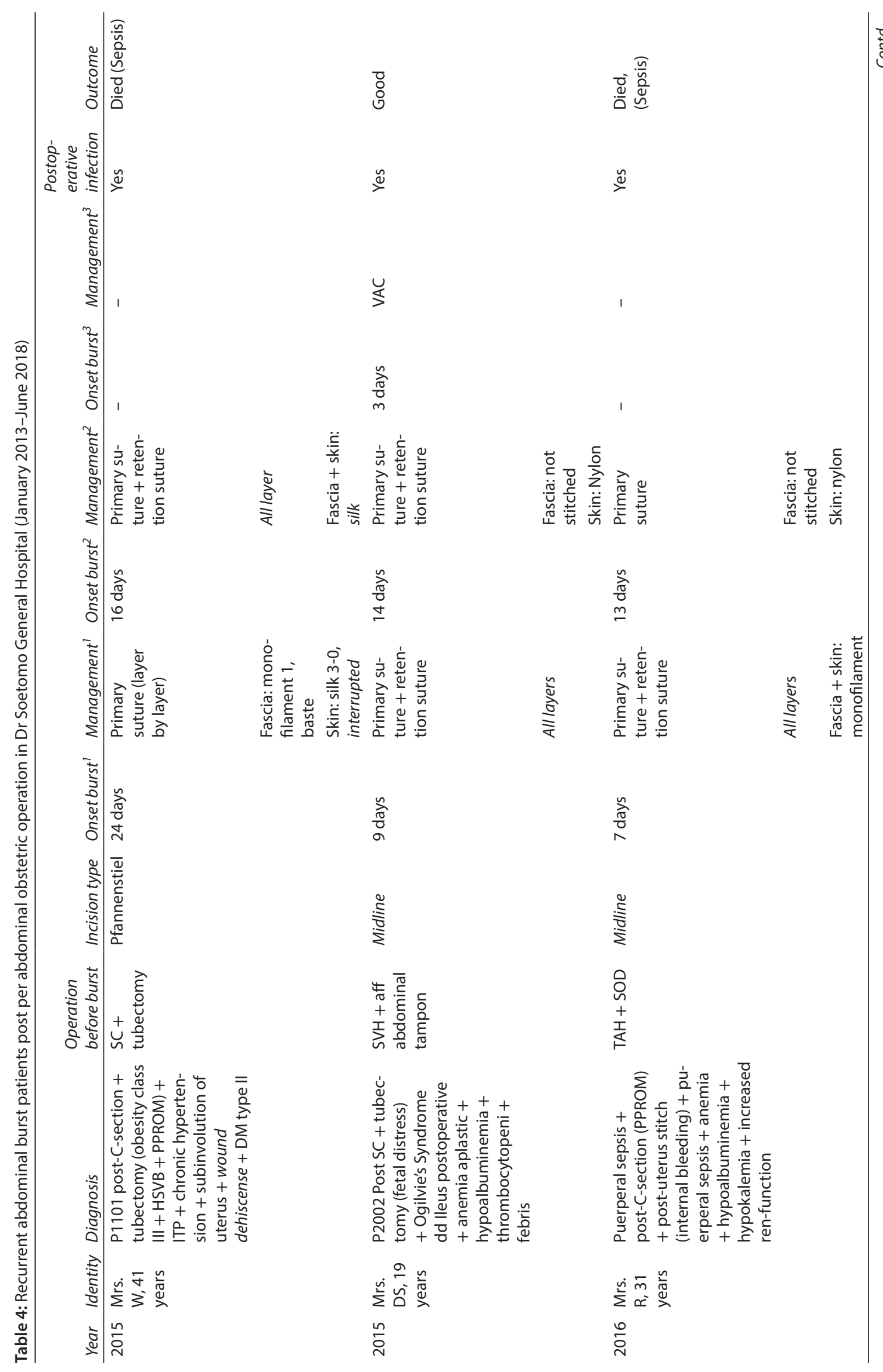




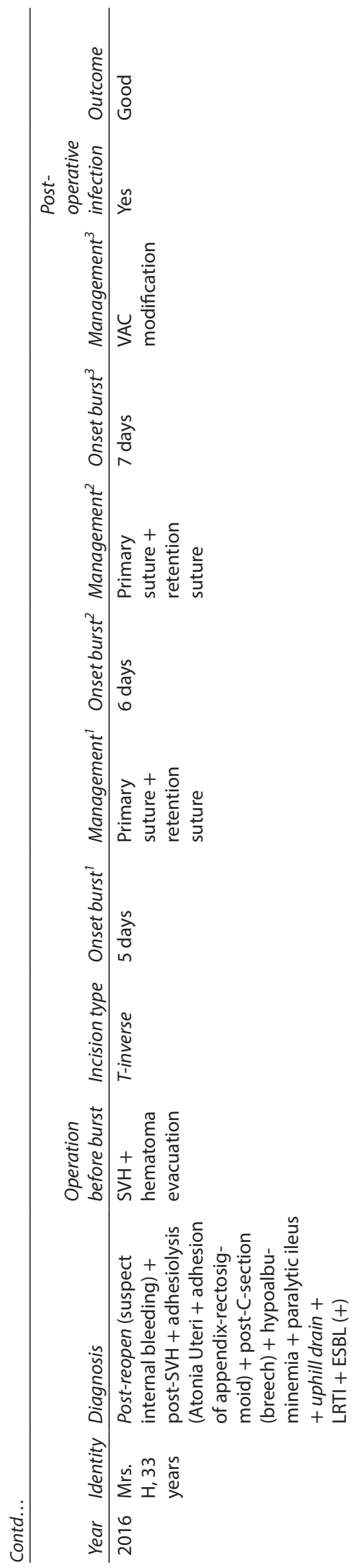

¿
$\stackrel{0}{\rightleftharpoons}$

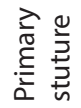

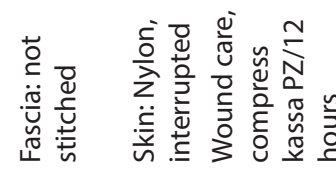

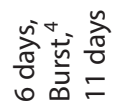

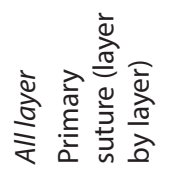

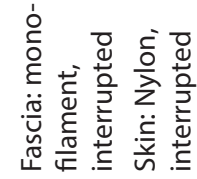

$\underset{\substack{\hat{\pi} \\ 0}}{0}$

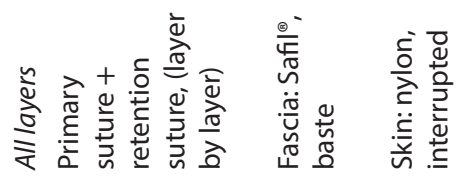

$\stackrel{\substack{\text { Iิ } \\=}}{=}$

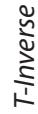

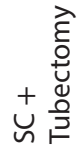

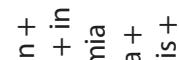

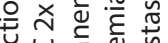

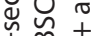

نे

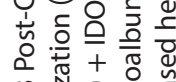

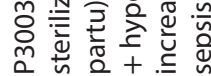

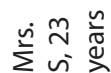

$\stackrel{\infty}{\stackrel{\infty}{N}}$ 
may separate the rectus sheath. It can also become the main risk factor of abdominal burst. ${ }^{13}$ Treatment for contaminated wounds must be done to identify the source of infection, e.g., intra-abdominal abscess or anastomosis leakage. Of all 5 recurrent abdominal burst cases, risk factors were found, either in postoperative or preoperative comorbidities, e.g., preterm premature rupture of membrane (PPROM), puerperal sepsis or autoimmune disease and steroid use. Colonies of the pathogen as an agent were found in all cases, around the wound and suture, mainly by Acinetobacter spp and Escherichia coli ESBL (+), which transmigrated from the gastrointestinal tract. Excessive use of cephalosporin and third-generation fluoroquinolone appears to increase the prevalence of ESBL. In most cases, prophylaxis antibiotic cefazolin $2 \mathrm{~g}$ was admitted intravenously 30 minutes before the surgery. Therapeutic antibiotic was also given after surgery based on culture. Therefore, as a consequence of selective pressure, postoperative peritonitis may be caused by multidrug bacteria, gram-negative bacteria and gram-positive, enterococci, and fungal infection in a bigger number. ${ }^{14}$ In three patients with a recurrent abdominal burst that happens more than twice, wound care using tissue culture and pus was done by the Clinical Microbiology Department. Antibiotic use is stopped when the sign of infection both clinically and laboratorially. Wound care without antibiotic using the aseptic concept shows a better outcome.

Wound care for recurrent abdominal burst patients in $\mathrm{Dr}$ Soetomo General Hospital requires a multidisciplinary team consisting of Departments of Obstetric \& Gynecology, Plastic Surgery, Digestive, Clinical Microbiology, Internal Medicine, Cardiology, Pulmonology, Anesthesiology, Psychiatric, Neurology, and Nutrition. In the second case, a vacuum-assisted closure (VAC) technique is used, and the fourth case is done using the VAC technique modified by plastic surgery team. Patients were treated in an isolation room in order to maintain the aseptic wound care. Two large VAC mechanisms are intended to measure the speed of wound healing, by reducing excessive interstitial fluid and toxic inflammation mediators and micro deformation mechanism on the wound surface and the surrounding skin together to release growth factors, corresponding to the expansion of new tissue. ${ }^{15}$ Choosing the VAC technique is done based on each patient's wound problem. In the second case, wound problem is slough, infection, and massive exudates. This is the underlying reason of using VAC with vacuum machine pulled by continuous pressure, reducing the exudate production and reduced colonies of bacteria. The vacuum is continued intermittently in 4 hours time period. While for the fourth case, massive exudate is found without signs of infection. This is the underlying reason of using a modified VAC by the plastic surgery department of Dr Soetomo General Hospital, using two bottles as vacuum and drainage and infusion tube. This modified VAC works to suction the exudates and is used intermittently. Patient and the family were taught to vacuum every 4 hours (Figs 1 and 2).

Both patients underwent wound care using dressing, changed every 5 days, with a long time of care (70 and 136 days). Using the VAC, both machine and modified, the patients were allowed for room mobilization, adequate macronutritions, and micronutritions were also given to speed the healing process. Both patients were evaluated clinically and laboratorially, where the $\mathrm{Hb}$ is maintained above $12 \mathrm{~g} / \mathrm{dL}$ and albumin above $3 \mathrm{~g} / \mathrm{dL}$. Both patients were then sent home with the modified VAC and were taught about home care. The wound in both patients has closed after 34 and 38 days after the dismissal, without complication. This finding is similar to the previous study involving 207 patients in Korea, which stated that the right VAC is adequate dehiscence care to post laparotomy wound, with a low failure rate compared to conventional care, $0 \%$ and $14.3 \%(p=0.002){ }^{16}$

Another patient was treated with conservative technique, using open abdomen care and gauze compress and normal saline. Conservative care is a choice for patients with disabilities and a poor general condition or at high risk of complications if re-surgery is done. ${ }^{17}$ Antibiotic was stopped, due to no sign of infection both clinically and laboratorially. The patient was treated using gauze compress, and normal saline changed every 12 hours and high protein nutrition during care. The treatment was shorter than using the other methods, only 48 days of care. The patient was then sent home and was taught about the aseptic wound care, and asked to come every 3 days to the Dr Soetomo General Hospital. The wound was fully healed 67 days after dismissal without complications (Fig. 3).

The mortality rate caused by abdominal burst is different in many studies. One study by Wolff stated that the mortality rate reaches $11 \%$, while Hartzell and Winfield Hampton said $40 \% .{ }^{18}$ In a study by Parmar et al., in 2008 , the mortality rate is $10 \%{ }^{2}$ In both death cases, recurrent abdominal burst and sepsis were found. Risk factors of puerperal sepsis before surgery increase the incidence of recurrent abdominal burst and worsen the sepsis.

The debate on how to prevent wound complications after primary surgeries has been going on for decades. A prevention strategy involving the facilities, environment, and experienced medical staffs to lower the morbidity and mortality in patients is needed. The infection factor as a wound closure failure predisposition is affected by epidemiological triad of a disease, e.g., host (patients' preoperative condition), agent (pathogenic bacteria), and the environment as a place that can influence the wound healing and bacterial growth. Paramedics, especially who are involved in the process of surgery, have to anticipate any complication. The standard of procedure must be done as instructed, and hand hygiene is also an important factor. Ideally, culture of microbe in the ward should be done annually, but it is still not yet implemented in Dr Soetomo General Hospital.

The limitations of this study are the incompleteness of the surgery report, and also the small size of the study sample. Therefore, we cannot compare significantly about the treatment of recurrent abdominal burst and the complications that happen because of each wound care methods. A bigger and long-term study is needed to examine some easy and effective wound care methods to lessen the treatment period and morbidity in recurrent abdominal burst cases.

\section{Conclusion}

Complication of abdominal burst is $0.4 \%$ post per abdominal surgery in obstetric done in Dr Soetomo General Hospital from January 2013 until June 2018. Mortality rate is $6.7 \%$ of all obstetric abdominal burst cases, contributing as $0.02 \%$ in maternal mortality rate in Dr Soetomo General Hospital. Most preoperative risk factors were from the host, e.g., anemia, hypoalbuminemia, and predisposition diseases (for example obesity, diabetes mellitus, and autoimmune disease). Operative and postoperative risk factors were influenced by the type of incision, thread, suturing technique, type and condition of surgery, and postoperative care. The prevention 


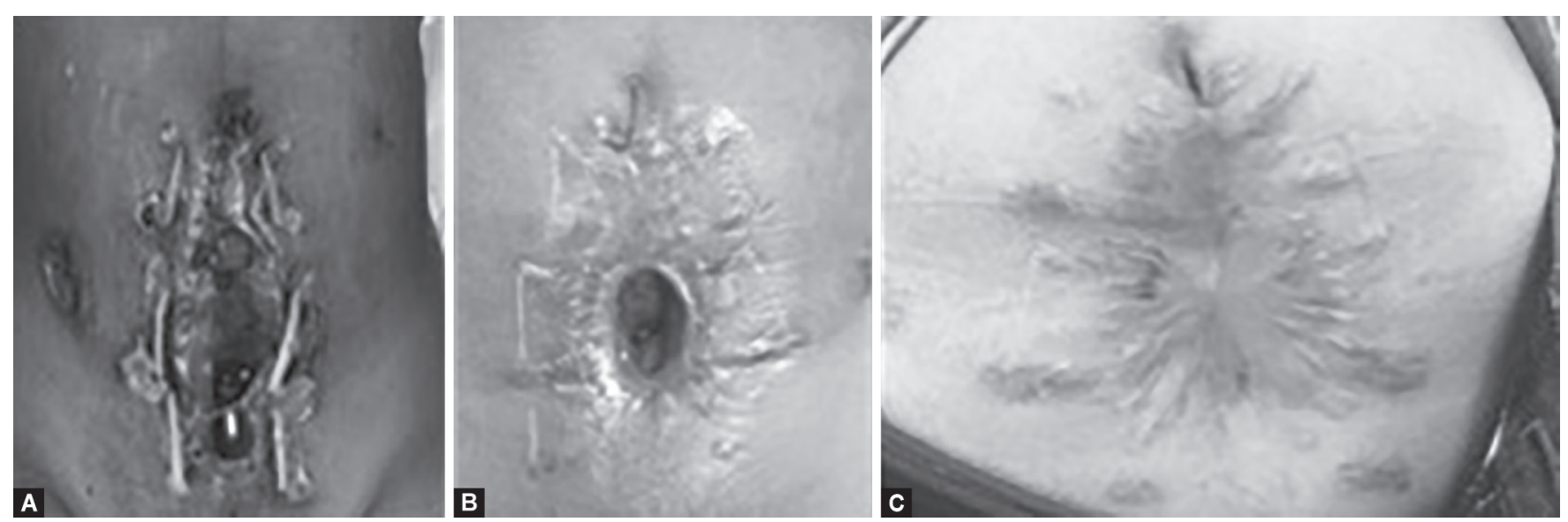

Figs $1 \mathrm{~A}$ to $\mathrm{C}$ : Wound healing in the second case: (A) Day 45 of care after the third burst, before VAC; (B) Day 125 of care, after VAC for 75 days; (C) Wound closes after 38 days of home care
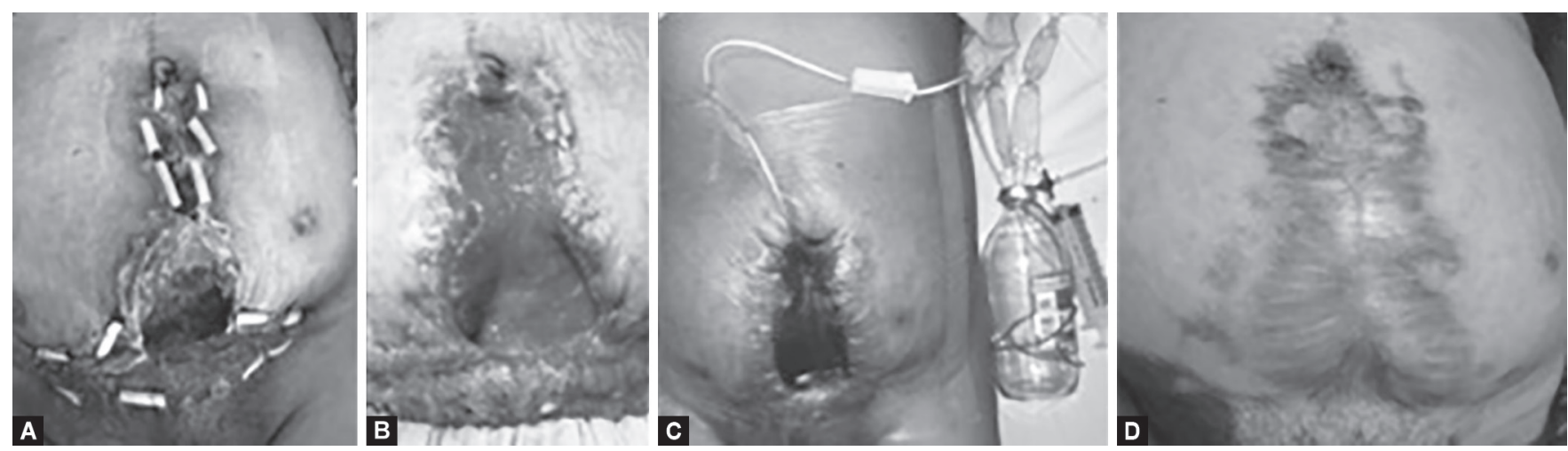

Figs 2A to D: Wound healing in the fourth case: (A) Day 26 of care after the third burst, before VAC; (B) Day 40 of care, with absorbent; (C) Day 42 of care, with modified VAC; (D) Wound closes after 34 days of home care
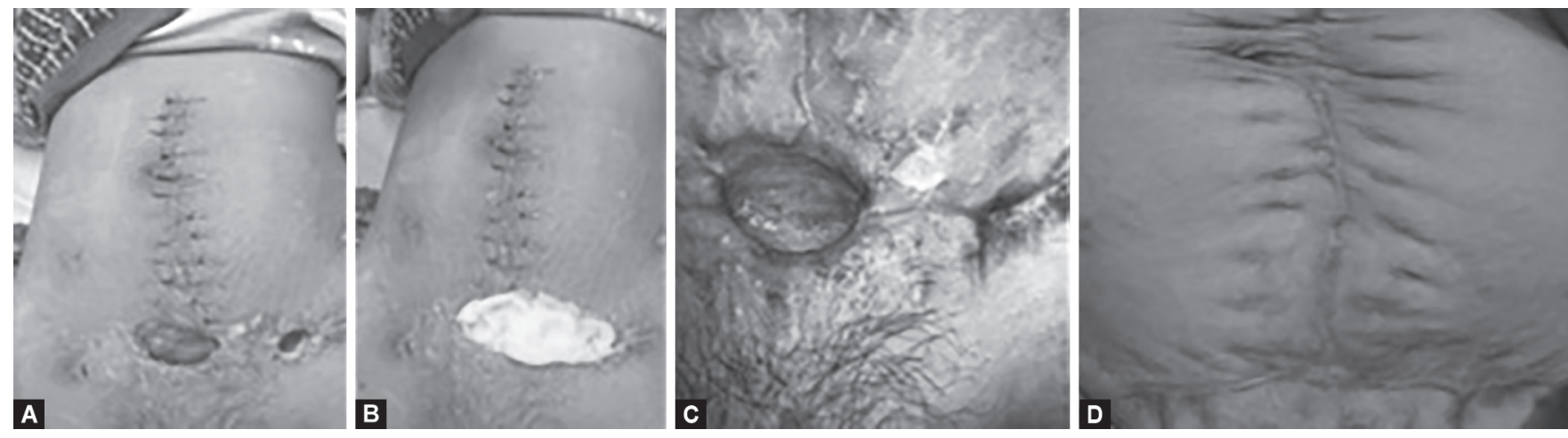

Figs 3A to D: Wound healing in the fifth case with conservative care: (A) Day 24 of care after the fourth burst; (B) Normal saline gauze compress care; (C) Day 48 of care, at dismissal; (D) Wound closed at 67 days after the dismissal

of infection in either before, during, or after surgery is crucial. It is also an important thing to do when giving the postoperative care inward, and preventing nosocomial agent transmission is an important thing to do. One-third of abdominal burst patients had recurrency, which caused a very long period of care, influencing their physical, mental, and social condition. Recurrent abdominal burst needs a multidisciplinary treatment, depending on the patient's wound problem. Two deaths were found in the recurrent abdominal burst cases, and both related to sepsis, while the other patients' wound has closed without any complications. A good prevention strategy involving the facilities, environment, and experienced medical staffs to lower the morbidity and mortality in patients is needed.

\section{References}

1. Dare FO, Bako AU, Ezechi OC. Abdominal burst following caesarean section: A preventable surgical complication. J Obstet Gynaecol 2000;20(6):612-613. DOI: 10.1080/01443610020001468.

2. Parmar G, Gohil A, Hathila V. Abdominal burst - A grave postoperative complication. The Int J Surg 2008;20(1):1-9. 
3. Mahey R, Ghetla S, Rajpurohit J, et al. A prospective study of risk factors for abdominal wound dehiscence. Int Surg J 2017;4(1):24-28. DOI: 10.18203/2349-2902.isj20163983.

4. Wagner MS, Bedard MJ. Postpartum uterine wound dehiscence: $A$ case report. J Obstet Gynaecol Can 2006;28(8):713-715. DOI: 10.1016/ S1701-2163(16)32236-8.

5. Schein M, Rogers P. Schein's Common Sense Emergency Abdominal Surgery. New York: Springer Link; 2004.

6. Soni P, DayspriYes VB, DayspriYes A, et al. Abdominal burst: A postoperative morbidity. Int J Sci Stu 2015;3(6):175-178. DOI: 10.17354/ ijss/2015/417.

7. Burger JWA, Incisional Hernia: Etiology, Prevention, Treatment. Proefschrift ter verkrijging van de graad van doctor aan de Erasmus Universiteit Rotterdam; 2006.

8. Spiliotis J, Tsiveriotis K, Datsis A, et al. Wound dehiscence is still a problem in the 21th century: A retrospective study. World J Emerg Surg 2009;4(12):1-5. DOI: 10.1186/1749-7922-4-12.

9. Amini AQ, Khan NA, Ahmad J, et al. Management of abdominal wound dehiscence: Still a challenge. Pak J Surg 2013;29:84-87.

10. Singh Ahi K, Khandekar SM, Mittal SK, et al. Prevention of abdominal burst by interrupted closure: a comparative study of conventional continuous versus interrupted-X-type versus Hughes far-andnear interrupted abdominal Fascial closure in surgical patients. IOSR Journal of Dent Med Sci (IOSR-JDMS) 2017;16(2):21-30. DOI: 10.9790/0853-1602072130, Ver. VII.
11. Gislason H, Viste A. Closure of abdominal burst after major gastrointestinal operations: comparison of different surgical techniques and later development of incisional hernia. Our J Surg 1999;165:958-961.

12. Shukla HS, Kumar S, Misra MC, et al. Abdominal burst and suture material:a comparison of abdominal wound closure with monofilament nylon and chromic catgut. Indian J Surg 1981;43:487-491.

13. Van Ramshorst G, Nieuwenhuizen J, Hop WCJ, et al. Abdominal wound dehiscence in adults: development and validation of a risk model. World J Surg 2010;34:20-27. DOI: 10.1007/s00268-009-0277-y.

14. Hagel S, Scheuerlein H. Perioperative antibiotic prophylaxis and antimicrobial therapy of intra-abdominal infections. Viszeralmedizin 2014;30:310-316. DOI: 10.1159/000368582.

15. Conde-Green A, Chung TL, Holton LH, et al. Incisional negativepressure wound therapy versus conventional dressings following abdominal wall reconstruction. Ann Plast Surg 2013;71:394-397. DOl: 10.1097/SAP.0b013e31824c9073.

16. Ko YS, Jung SW. Vacuum-assisted close versus conventional treatment for postlaparotomy wound dehiscence. Ann Surg Treat Res 2014;87(5):260-264. DOI: 10.4174/astr.2014.87.5.260.

17. Arno D, Berrevoet $F$. Consequences of abdominal burst after midline laparotomy. Desertation. Netherlands: Faculty of Medicine and Health Sciences Ghent University; 2017.

18. Wolff WI. Disruption of abdominal wounds. Ann of Surg 1950;131:534555. DOI: 10.1097/00000658-195004000-00007. 